\title{
AVALIAÇÃO DA PRÁTICA PEDAGÓGICA DOCENTE NA ESCOLA POLITÉCNICA DE PERNAMBUCO
}

Thiany Maria Correia Matias Ferreira-tmcmf@poli.br

Escola Politécnica da Universidade de Pernambuco

Rua Benfica, 455

50.720-001 - Recife - Pernambuco

Anna Lúcia Miranda Costa - annalucia@poli.br

Escola Politécnica da Universidade de Pernambuco

Rua Benfica, 455

50.720-001 - Recife - Pernambuco

Bruna Souza Ávila Pessoa-bsap@poli.br

Escola Politécnica da Universidade de Pernambuco

Rua Benfica, 455

50.720-001 - Recife - Pernambuco

Jair Medeiros Ferreira Filho - jmff@ecomp.poli.br

Escola Politécnica da Universidade de Pernambuco

Rua Benfica, 455

50.720-001 - Recife - Pernambuco

Resumo: Com as novas demandas da sociedade, mudanças no contexto educacional se mostraram necessárias. Ao longo dos anos foi possível notar que muitos profissionais sem licenciatura migraram da sua profissão de origem para se tornarem professores com pouca ou quase nenhuma preparação para a docência. Dito isso, é notória a existência de didáticas ineficientes e ausência de estratégias pedagógicas voltadas para uma boa aprendizagem do aluno. Assim, o Projeto de Avaliação da Prática Pedagógica Docente existe desde 2016 na Escola Politécnica de Pernambuco, com o objetivo de avaliar e caracterizar as práticas pedagógicas desenvolvidas na Instituição e, assim, melhorar o ensino- aprendizagem. Desde sua primeira edição, se faz uso de um questionário com oito perguntas como forma de obter as avaliações de docentes e discentes. Para este artigo, optou-se por dar ênfase a uma questão, e, ao usar métodos quantitativos para a análise dos dados, foi possível comparar as respostas obtidas pelos alunos matriculados no Ciclo Básico e em cada curso das disciplinas do Ciclo Profissional. Como perspectiva de resultados inovadores para os anos de 2018 e 2019, destacam-se dois aspectos importantes para o Projeto: a análise das avaliações por curso e a criação de um 'site' para a realização da ação. Sendo assim, a coordenação reconhece a importância do Projeto, o qual se fortalece a partir de cada elemento inserido no desenvolvimento de suas respectivas edições.

Palavras-chave: Avaliação, Prática Pedagógica, Ensino-aprendizagem. 


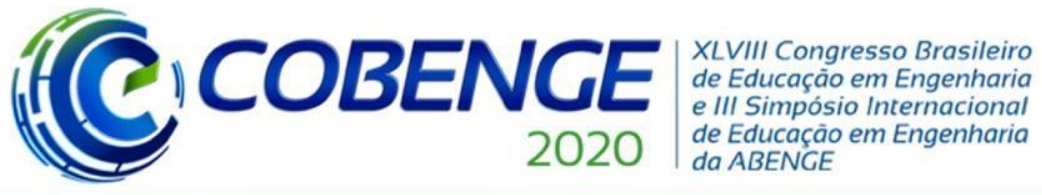

"Os desafios para formar hoje o engenheiro do amanhã"

\section{INTRODUÇÃO}

Os avanços tecnológicos e sociais exigem mudanças no panorama educacional em que se necessita da formação de profissionais cada vez mais qualificados frente a uma prática da docência frequentemente assumida como outra opção de trabalho por profissionais com apenas o bacharelado (VEIGA; RESENDE; FONSECA, 2000). Sem uma preparação prévia, tornam-se professores de forma repentina, e assim, espera-se que aproveitem as oportunidades de acessar os conhecimentos específicos da profissão docente (CHIARELLO; PIECKZOWKI, 2018).

Em virtude do pensamento pedagógico anterior aos anos 1980, de vertente mais tecnicista, o professor deveria ter a organização, autoridade e dedicação como qualidades pessoais (SCHWARTZ; BITTENCOURT, 2012). Os que assumem esta condição acabam aprendendo a ser docentes pela própria experiência, o que, em geral, se dá como um esforço solitário, sem os benefícios de uma sistematização racional de procedimentos (BAZZO, 1998). Devido a esta formação, muitas vezes fundamentam-se na ideia de que é possível ensinar os outros por meio da explicação oral, concentrando todos os seus esforços no sentido de condensar seus conhecimentos e de expô-los de forma lógica e clara.

De acordo com as atuais demandas educacionais sugeridas pelo Plano Nacional de Educação (BRASIL, 2014), a atitude do professor especialista dá lugar a um profissional da aprendizagem que incentiva o aprendiz, considerando que cabe à educação assumir efetivamente seu papel de instrumento essencial na formação de um profissional humanizado, crítico e ético. Neste sentido, o professor é elemento essencial para a aprendizagem do estudante, sendo inerente ao papel docente cuidar do processo educativo, adotando estratégias de ensino e de avaliação adequadas às necessidades de aprendizagens (GALVÃO; CÂMARA; JORDÃO, 2012).

A Escola Politécnica de Pernambuco (POLI), por meio do Núcleo de Apoio Psicopedagógico Inclusivo (NAPSI) buscou identificar como a Instituição se insere no contexto exposto acima. Com atuação centenária, a POLI se destaca por ofertar excelência técnica na formação de engenheiros. Formada por um corpo docente de reconhecida titulação e competência, compromete-se continuamente com a qualificação do processo de ensino e aprendizagem. Como acontece em outras instituições de ensino em engenharia, o docente da POLI, em sua maioria, é bacharel com formação em stricto sensu (mestrado e doutorado) que, apesar dos destaques em suas respectivas áreas de atuação, possuem pouco ou nenhum conhecimento de natureza pedagógica.

Neste sentido, o NAPSI vem executando desde 2016 o Projeto de Avaliação da Prática Pedagógica Docente com o objetivo de caracterizar e avaliar continuamente as práticas pedagógicas desenvolvidas na Instituição. Admite como finalidade oferecer subsídios sobre dados relevantes ao processo de ensino e aprendizagem para auxiliar o professor nas tomadas de decisão sobre o seu trabalho, coerentes com as novas demandas educacionais.

O Projeto fundamenta-se a partir do princípio de que a prática pedagógica se constitui numa relação de reciprocidade e de práxis, na qual professor e aluno compartilham decisões favoráveis à melhoria do ensino e da aprendizagem (SAUL, 2010). A partir deste princípio, se compreende a avaliação da aprendizagem como elemento constituitivo do ato educativo (LUCKESI, 2011). Desde uma perspectiva formativa, o processo avaliativo se compromete com o atendimento às necessidades de aprendizagens do estudante, reconhecendo seu efetivo espaço enquanto protagonista do percurso formativo que vivencia (ALBUQUERQUE; OLIVEIRA, 2009).

Desta forma, considerando que este Projeto é uma ação contínua, apresenta-se neste artigo um recorte referente a uma perspectiva extraída de um questionário acerca da prática avaliativa da POLI. Acredita-se que as respostas a uma das questões propostas apontariam indícios da vivência, ou não, de uma prática avaliativa baseada numa relação de reciprocidade e de respeito. Visto que, as ações do professor em sala de aula influenciam diretamente na aprendizagem, a 
"Os desafios para formar hoje o engenheiro do amanhã"

coordenação do Projeto considera as relações entre eles como fatores determinantes de um clima favorável a esta aprendizagem (ALBUQUERQUE; OLIVEIRA, 2009).

\section{METODOLOGIA}

O Projeto da Avaliação da Prática Pedagógica Docente da Escola Politécnica da Universidade de Pernambuco teve sua primeira edição em 2016. Desde sua primeira versão, uma das intenções é a de obter um maior número possível de respondentes (professores e alunos), considerando a necessidade do Projeto de se tornar conhecido pela comunidade acadêmica. Este objetivo ainda prevalece e justifica a metodologia apresentada neste artigo.

De perspectiva quantitativa apenas para coleta dos dados, a metodologia utilizada se desenvolveu através da aplicação de um instrumento (questionário) de múltipla-escolha com oito questões amplamente discutidas pela coordenação do Projeto. Pensou-se, ao utilizar o método citado, uma possível realização de estudos estatísticos das respostas, análise dos dados e maior aderência, para, assim, entender o contexto geral, já que, "quanto maior a área representada, menor o detalhamento contido na imagem; quanto menor o recorte do objeto original, maior a possibilidade de copiar os detalhes." (PEREIRA; ORTIGÃO, 2016, p. 72).

Com o objetivo de institucionalizar o Projeto, inserindo-o numa cultura de qualificação do processo de ensino-aprendizagem da POLI, estão sendo feitos aprimoramentos nos processos metodológicos e administrativos. Um exemplo deste esforço é a disponibilização de uma bolsa de auxílio estudantil para um dos alunos participantes. Assim, visando à obtenção de diferentes pontos de vista, o bolsista, juntamente com os docentes e discentes, atua como parte da coordenação.

No ano de 2018, tanto discentes quanto docentes responderam o formulário, ambos de forma anônima e espontânea. É válido pontuar que: podiam responder o questionário somente os alunos matriculados nas disciplinas no devido período e os professores que a lecionavam. Como forma de confirmação de identidade, foi solicitado o CPF de ambos para um melhor controle da quantidade de avalições por pessoa, permitindo somente uma por disciplina.

A divulgação do cronograma de aplicação do questionário foi feita por meio das redes sociais e canais oficiais de comunicação do Diretório Acadêmico e do Núcleo de Apoio Psicopedagógico Inclusivo (NAPSI), além de cartazes espalhados pela Instituição, os quais continham o link que direcionava à página da avaliação. O formulário em 2018 foi providenciado de forma online em uma plataforma própria para execução da ação, facilitando assim, a obtenção dos resultados gerais de cada pergunta, que foram divulgados em banners pela POLI. Os resultados individuais foram entregues em mãos aos coordenadores de cada curso para que eles entregassem aos docentes, sempre respeitando as questões éticas.

Outra evolução perceptível está relacionada à análise dos dados, feita agora por curso. Para realizá-la, foram transferidos os dados para o Excel 2010 para serem separadas as disciplinas do Ciclo Básico das disciplinas do Ciclo Profissional de todas as engenharias da POLI: Civil, Computação, Controle e Automação, Elétrica - Eletrônica, Elétrica - Eletrotécnica, Elétrica Telecomunicações e Mecânica Industrial. Ao separar dessa forma, pôde-se avaliar melhor as nuances de cada pergunta, pois, ao focar em cada curso, é analisada a necessidade individualmente, traçando assim, estratégias diferentes para cada grupo.

Em busca do aperfeiçoamento mencionado, a coordenação do Projeto optou por dedicar o ano de 2019 para a criação de um 'site' exclusivo, elaborado por um aluno de Engenharia da Computação da POLI com o auxílio de outros alunos. A decisão foi feita baseada na busca pela melhora do sistema de recolhimento de dados. 


\section{RESULTADOS}

O Projeto foi utilizado por alunos e professores como estratégia de participação no processo educacional. Esta importância se consolida na medida em que a avaliação é realizada e os resultados chegam, sendo possível subsidiar as tomadas de decisão pedagógicas e administrativas.

Para produção deste artigo, optou-se por dar ênfase a uma única questão, dentre as oito propostas pelo questionário (Quadro 1), por concordar com Albuquerque e Oliveira (2009) ao afirmarem que o estudante compartilha com o docente o protagonismo do ato avalitivo. A coordenação acreditou que as respostas referentes à Questão 5 expressariam esta concepção no momento da devolução das atividades avaliativas (exercícios, provas, seminários, projetos, etc), em que o docente proporcionaria ao estudante a oportunidade de participar efetivamente do processo ensino-aprendizagem.

Quadro 1 - Questões presentes no questionário.

\begin{tabular}{|l|}
\hline $\begin{array}{l}\text { 1. O professor disponibilizou o plano de ensino do componente curricular } \\
\text { contendo objetivos, ementa, conteúdos, metodologia, critérios de avaliação e } \\
\text { bibliografia? }\end{array}$ \\
\hline $\begin{array}{l}\text { 2. Os conteúdos trabalhados estavam coerentes com os que constavam no } \\
\text { plano do componente curricular? }\end{array}$ \\
\hline $\begin{array}{l}\text { 3. Os conteúdos foram trabalhados com clareza, objetividade e de forma } \\
\text { organizada? }\end{array}$ \\
\hline $\begin{array}{l}\text { 4. As avaliações possuíam nível e abrangência compatíveis com os conteúdos } \\
\text { trabalhados durantes as aulas? }\end{array}$ \\
\hline $\begin{array}{l}\text { 5. Os resultados das atividades foram apresentados e discutidos em sala de aula } \\
\text { com os estudantes? }\end{array}$ \\
\hline $\begin{array}{l}\text { 6. O professor do componente curricular era pontual (chegava no horário da } \\
\text { aula)? }\end{array}$ \\
\hline $\begin{array}{l}\text { 7. O professor do componente curricular era assíduo (tinha frequência } \\
\text { constante)? }\end{array}$ \\
\hline 8. A relação entre professor e aluno era ética e respeitosa? \\
Fonte: Comissão Setorial de Avaliação da POLI.
\end{tabular}

Comparado com a primeira edição, identifica-se um aumento de $64 \%$ na adesão do alunado. O questionário era do tipo múltipla escolha, em que os avaliadores optavam por uma das respostas dentre as três alternativas: 'sempre', 'às vezes' e 'nunca', e, quando nenhuma das opções era escolhida, automaticamente aparecia nos resultados como 'não respondeu'.

Quanto à distribuição destas respostas, segue o registrado: a maior quantidade é de estudantes do Básico com 1085 avaliações; Computação vem em segundo com 123; em seguida, Civil com 115; Elétrica-Eletrotécnica 72; Controle e Automação 61; Elétrica-Eletrônica 56; Mecânica Industrial 33; Elétrica-Telecomunicações 09.

A Figura 1 apresenta os resultados adquiridos com as avaliações dos cursos de Engenharia Elétrica-Eletrônica, Engenharia Elétrica-Eletrotécnica, Engenharia Elétrica-Telecomunicações e Engenharia de Controle e Automação: 
Figura 1 - Indicador 5: Os resultados das atividades foram apresentados e discutidos em sala de aula com os estudantes?

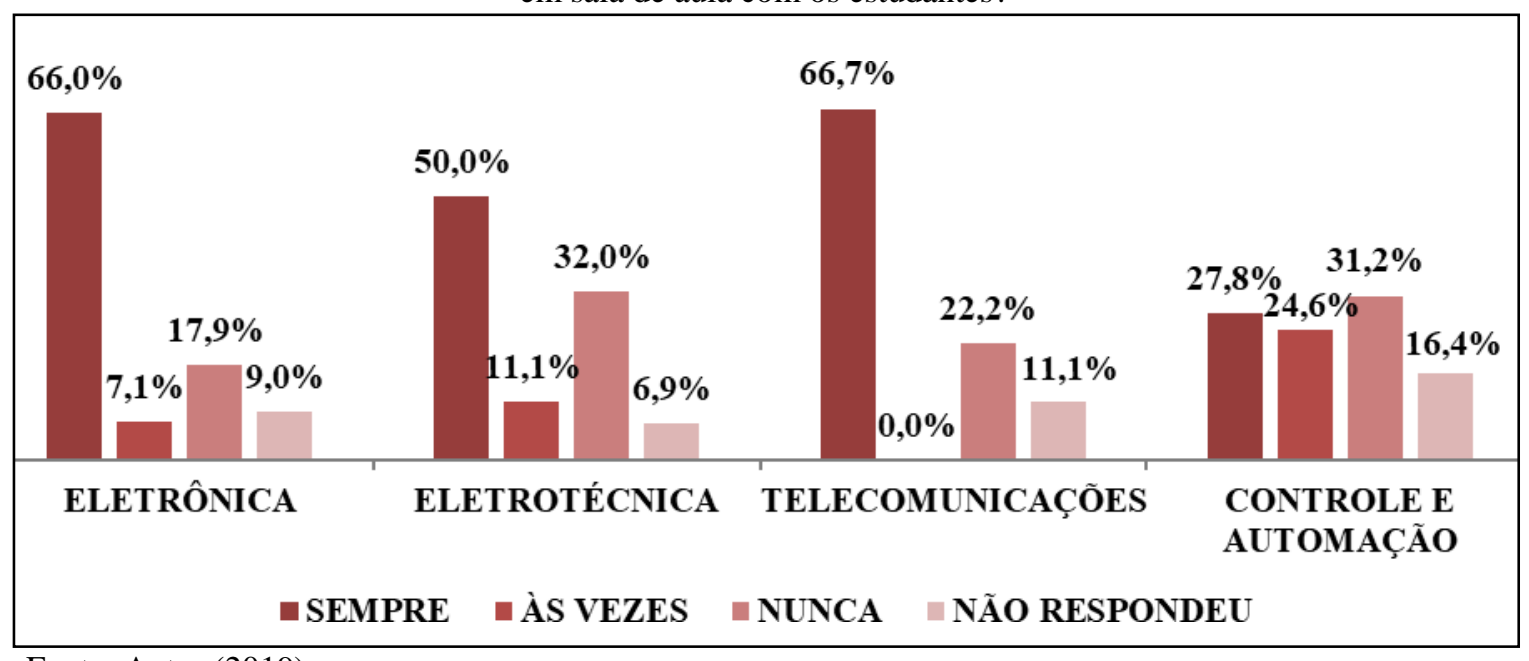

Fonte: Autor (2019).

Lembrando que: estas são as respostas obtidas nas avaliações das disciplinas do Ciclo Profissional de cada curso. Na Figura 1 é possível visualizar que nos cursos de Eletrônica, Eletrotécnica e Telecomunicações há a predominância da opção 'sempre', 66,0\%, 50,0\% e $66,7 \%$ respectivamente. Em seguida, 'às vezes' com 7,1\%, 11,1\% e 0,0\%; 'nunca' 17,9\%, $32,0 \%$ e $22,2 \%$; e os que não responderam, $9,0 \%, 6,9 \%$ e $11,1 \%$, respectivamente. Porém, em Controle e Automação existe uma maior distribuição das respostas: 'sempre' com $27,8 \%$; 'às vezes' com 24,6\%; e os que não responderam com 16,4\%, sendo o predomínio da opção 'nunca' com $31,2 \%$, o que leva a entender que a maioria dos professores deste curso não discutem em sala os resultados das provas. Além disso, nessa figura, a porcentagem dos que não responderam foi relativamente alta se comparada aos outros cursos.

A Figura 2 mostra os resultados obtidos nas avaliações das disciplinas do Ciclo Profissional do curso de Engenharia Civil:

Figura 2 - Indicador 5: Os resultados das atividades foram apresentados e discutidos em sala de aula com os estudantes?

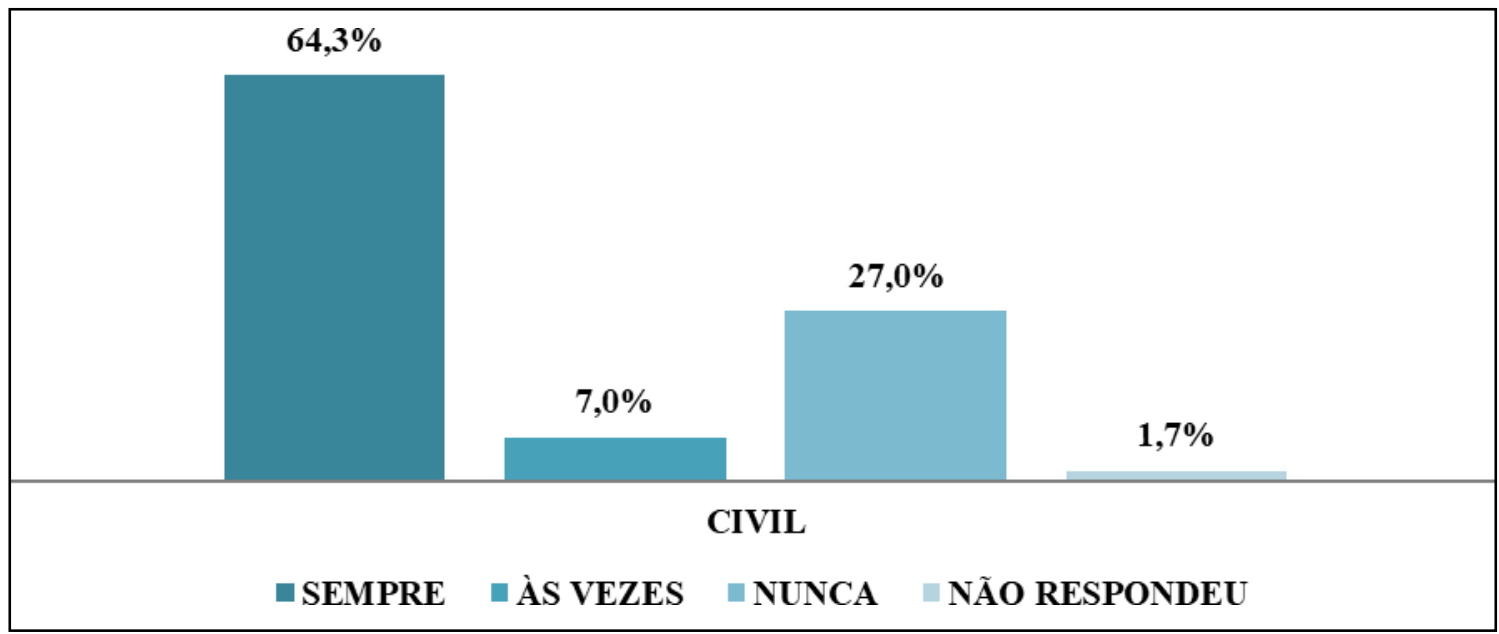

Fonte: Autor (2019).

Os resultados obtidos, mostrados na Figura 2, permitem afirmar que mais da metade dos avaliadores responderam que os professores discutem os resultados das provas em sala, comprovado pela porcentagem da opção 'sempre', com 64,3\%; já os que afirmam nunca ter tido 
(C) COBENCE 2020

"Os desafios para formar hoje o engenheiro do amanhã"
$\mathrm{O1}$ a $\mathrm{O3}$ de dezembro Evento On-line

as discussões sobre os resultados em sala, correspondem à $27,0 \%$; 'às vezes' com 7,0\%; e somente $1,7 \%$ das pessoas não responderam, ou seja, quase $100 \%$ dos avaliadores responderam o questionário, algo muito importante para a proposta do Projeto: conseguir o maior número de respondentes possível para, assim, obter um resultado mais próximo da realidade.

Na Figura 3 e na Figura 4, é possível observar os resultados recolhidos nas avaliações das disciplinas do Ciclo Profissional do curso de Engenharia Mecânica Industrial e Engenharia da Computação, respectivamente:

Figura 3 - Indicador 5: Os resultados das atividades foram apresentados e discutidos em sala de aula com os estudantes?

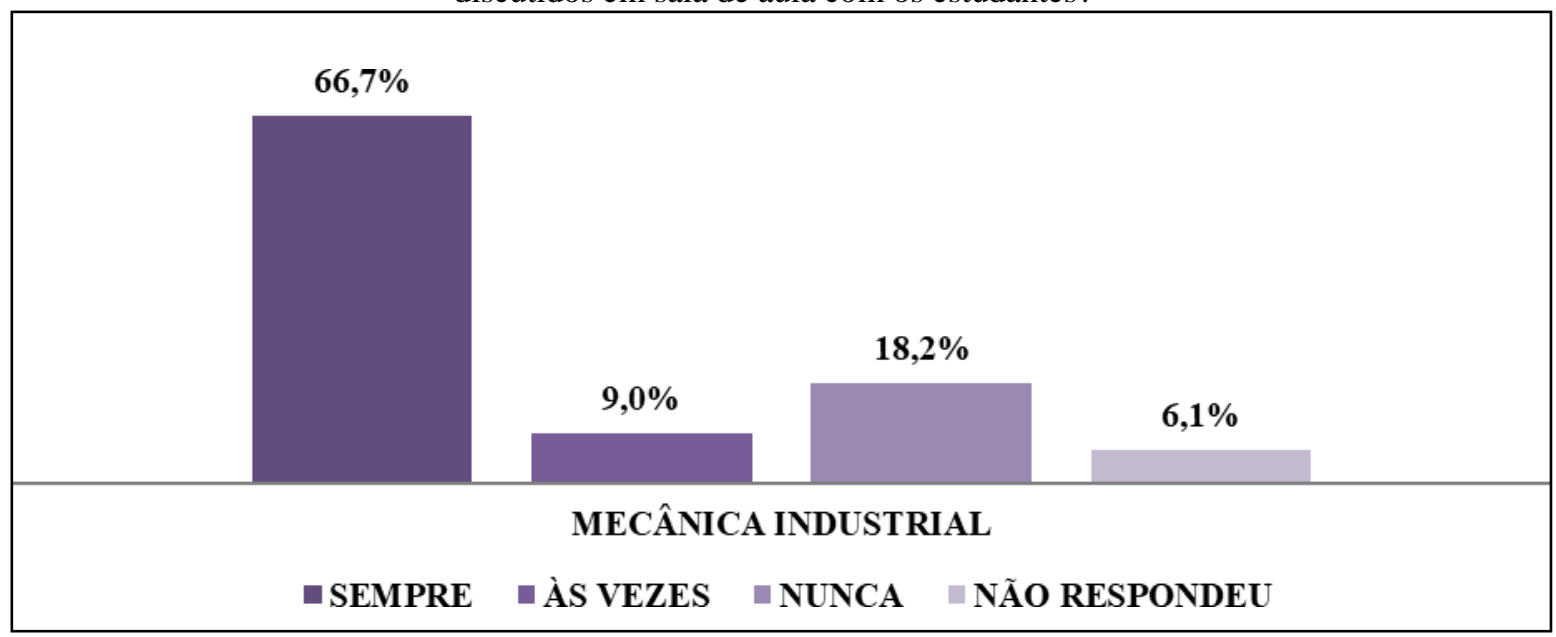

Fonte: Autor (2019).

Figura 4 - Indicador 5: Os resultados das atividades foram apresentados e discutidos em sala de aula com os estudantes?

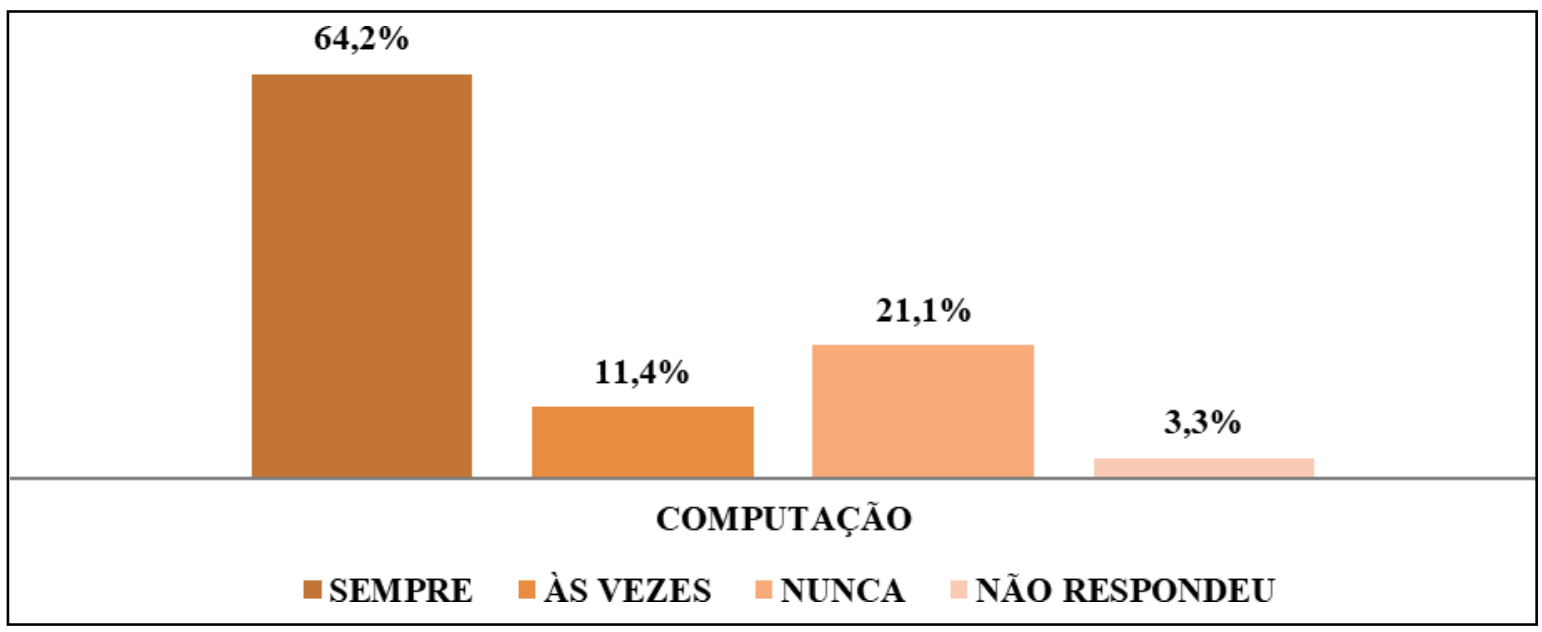

Fonte: Autor (2019).

Em ambas as Figura 3 e Figura 4, mais uma vez, a superioridade nas respostas é da opção 'sempre', com 66,7\% e 64,2\% respectivamente. A opção 'às vezes' com 9,0\% e 11,4\% respectivamente; e 'nunca' teve uma redução considerável em relação às porcentagens das figuras anteriores, com $18,2 \%$ e $21,1 \%$ respectivamente, algo favorável, pois mostra que boa parte dos professores faz a discussão dos resultados em sala. Além disso, o percentual de avaliadores que não responderam também foi pequeno em Computação, com 3,3\%, se destacando em relação à Mecânica, que obteve 6,1\%. 
A Figura 5 apresenta os resultados do Ciclo Básico, ciclo este com duração de quatro semestres que engloba disciplinas as quais todos os estudantes da POLI precisam cursar, independente do curso de graduação:

Figura 5 - Indicador 5: Os resultados das atividades foram apresentados e discutidos em sala de aula com os estudantes?

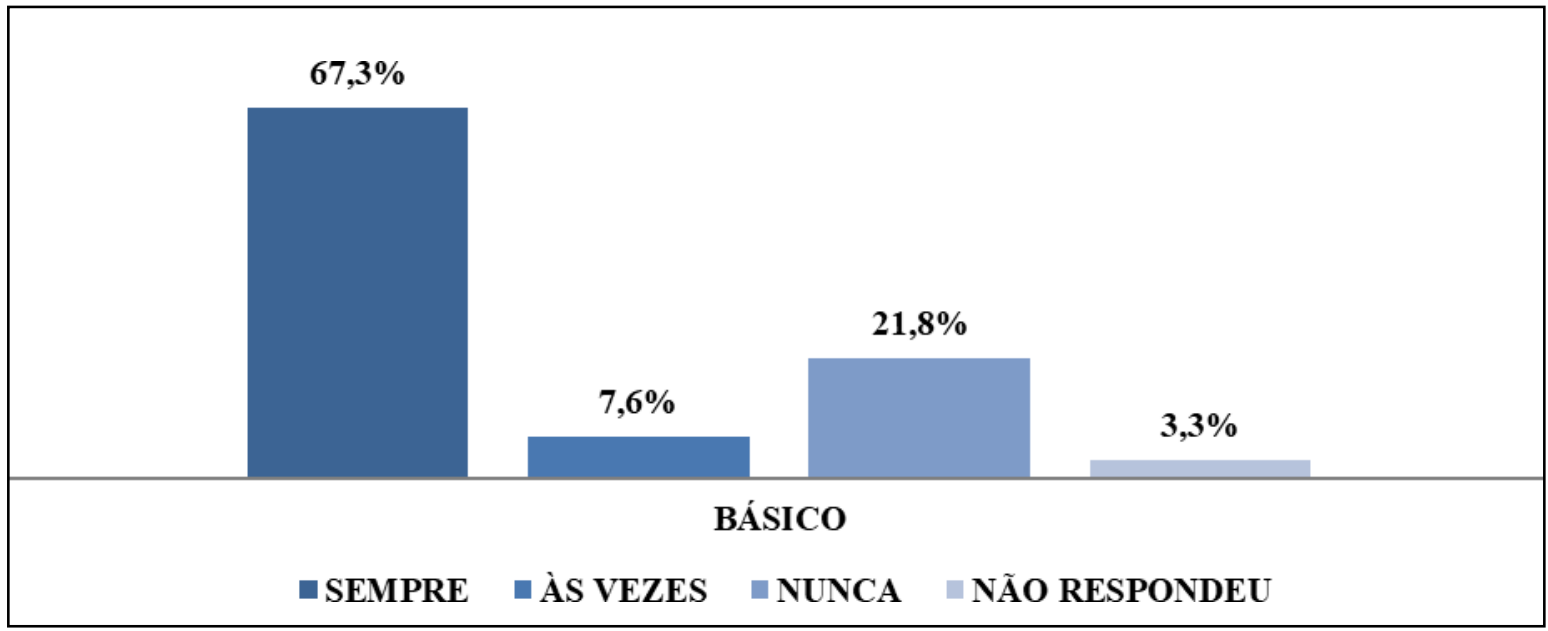

Fonte: Autor (2019).

O destaque na Figura 5 é o pequeno percentual da coluna 'não respondeu', com 3,3\%, devido à grande quantidade de avaliações obtidas no Ciclo Básico. A coluna de 'sempre' corresponde a mais da metade das respostas, com 67,3\%; 'às vezes' com 7,6\%; e a de 'nunca' com 21,8\%. Desta forma, tendo em mente que todos os alunos passam pelo Ciclo Básico, percebe-se a criação de um hábito de discussão dos resultados das provas com os professores, algo que, em alguns cursos, é perdido no Ciclo Profissional. Assim, é notória a necessidade de solicitar e estimular os professores a criar este hábito para uma melhora no ensinoaprendizagem com o intuito de diminuir a discrepância entre os dois ciclos.

\section{CONSIDERAÇÕES FINAIS}

Com a crescente adesão da comunidade acadêmica na realização da avaliação durante as edições, é notório que a mesma reconhece o Projeto como importante ferramenta de melhora no processo educativo. Este reconhecimento pode ser entendido como a validação do Projeto na cultura avaliativa da própria Instituição. Para os docentes, este reconhecimento exposto a partir da participação dos mesmos em uma autoavaliação, mostra que há uma preocupação com sua prática docente. Dito isto, é possível validar a ação como promovedora de dados que se tornam subsídios para as tomadas de decisão, auxiliando os docentes na busca da melhora de suas ações e de como elas influenciam na aprendizagem do aluno.

Quanto à participação dos discentes, buscou-se alinhar o notório aumento da adesão com as experiências vivenciadas pelos mesmos nas edições anteriores. É importante ressaltar que não houve participação de alunos do curso de Física de Materiais por ser este um curso implantado recentemente.

Como destacado anteriormente, o desenvolvimento de uma plataforma web exclusiva para o Projeto, é reconhecido pela equipe de coordenação como um elemento inovador. Considerando que esta ferramenta foi produzida por um aluno de Computação e integrante da equipe, pode-se afirmar que é uma ação capaz de ressignificar a cultura avaliativa de uma instituição centenária. Conclui-se destacando a constante busca pelo aprimoramento metodológico por parte da coordenação, tentando, assim, obter uma maior participação ao Projeto. 


\section{Agradecimentos}

Gostaríamos de agradecer a todos os membros atuantes deste Projeto que de alguma forma contribuíram e/ou contribuem para que ele siga em frente, melhorando a cada edição. Gratidão também, à equipe de Gestão da Escola Politécnica de Pernambuco, e ao diretor José Roberto Cavalcanti por nos apoiar desde o início. E, especialmente, aos integrantes do Núcleo de Apoio Psicopedagógico Inclusivo (NAPSI) que estão sempre ao nosso lado e nos dão o suporte do dia a dia.

\section{REFERÊNCIAS}

ALBUQUERQUE, Targélia de Souza; OLIVEIRA, Eloiza da Silva Gomes. Avaliação Educacional. Curitiba: IESDE Brasil, 2009.

BAZZO, Walter Antonio. Ensino de engenharia: novos desafios para formação docente. 1998. Tese (Doutorado) - Centro de Ciências da Educação, Universidade Federal de Santa Catarina, Florianópolis, 1998. Disponível em:

https://repositorio.ufsc.br/xmlui/handle/123456789/77680. Acesso em: 30 mar. 2020.

BRASIL. Lei n.13.005, de 25 de junho de 2014. Aprova o Plano Nacional de Educação PNE e dá outras providências. Diário Oficial da União, Brasília, DF., 2014. Disponível em: http://pne.mec.gov.br/18-planos-subnacionais-de-educacao/543-plano-nacional-deeducacao-lei-n-13-005-2014

CHIARELLO, E. C; PIECZKOWSKI, T. M. Z. Práticas Pedagógicas do bom professor atuante em Engenharia Civil. Imagens da Educação, Maringá, v.8, n.1, p. e40351, 2018. Disponível em: http://www.periodicos.uem.br/ojs/index.php/ImagensEduc/article/view/40351. Acesso em: 26 mar. 2020.

GALVÃO, A.; CÂMARA, J.; JORDÃO, M. Estratégias de aprendizagem: reflexões sobre universitários. Revista Brasileira de Estudos Pedagógicos, Brasília, v.93, n.235, p. 627-644, 2012. Disponível em: https://www.scielo.br/pdf/rbeped/v93n235/06.pdf. Acesso em: 30 mar. 2020.

LUCKESI, Cipriano Carlos. Avaliação da aprendizagem componente do ato pedagógico. São Paulo: Cortez, 2011.

PEREIRA, G.; ORTIGÃO, M. I. R. Pesquisa Quantitativa em Educação: Algumas Considerações. Revista Periferia, v. 8, n. 1, p. 66-79, 2016. Disponível em: https://www.epublicacoes.uerj.br/index.php/periferia/article/view/27341. Acesso em: 04 abr. 2020.

SAUL, Ana Maria. Avaliação emancipatória: desafio à teoria e à prática de avaliação e reformulação de currículo. São Paulo: Cortez, 2010.

SCHWARTZ, Suzana; BITTENCOURT, Zoraia A. Professores e alunos do ensino superior: Suas concepções sobre os processos de ensino e de aprendizagem e sobre o que significa se um "bom professor". In: IX Seminário de pesquisa em educação da região sul, 2012, Porto Alegre. Anais. Caxias do Sul, 2012. Disponível em: 
"Os desafios para formar hoje o engenheiro do amanhã"

http://www.ucs.br/etc/conferencias/index.php/anpedsul/9anpedsul/paper/viewFile/1423/976.

Acesso em: 27 mar. 2020.

VEIGA, Ilma Passos Alencastro; RESENDE, Lúcia Maria Gonçalves de; FONSECA, Marília. Aula Universitária e Inovação. In: VEIGA, Ilma Passos Alencastro; CASTANHO, Maria Eugênia (org.). Pedagogia Universitária: a aula em foco. $1^{a}$. ed. Campinas: Ed. Papirus, 2000. p. 161-191.

\title{
EVALUATION OF TEACHING PEDAGOGICAL PRACTICE AT POLYTECHNIC SCHOOL OF PERNAMBUCO
}

\begin{abstract}
With the new demands of society, changes in the educational context proved to be necessary. Over the years, it was possible to notice that many professionals without an education degree migrated from their career of origin to become teachers, however they had no type of preparation for teaching. That said, it is notorious the existence of inefficient didactics and the absence of pedagogical strategies aimed at good student learning. Thus, the Teaching Pedagogical Practice Evaluation Project exists since 2016 at the Polytechnic School of Pernambuco, with the goal of evaluating and characterizing the teaching pedagogical practices developed at the Institution and, thus, improving teaching-learning. Since its first edition, a quiz with eight questions has been used as a way to obtain the evaluations of professors and students. For this article, was chosen to emphasize one question, and, by using quantitative methods for data analysis, it was possible to compare the responses obtained from the students of the Basic Cycle and in each course of the Professional Cycle subjects. With a perspective of innovative results for the years 2018 and 2019, stand out two important aspects for the Project: the analysis of the evaluations per course and the creation of a 'website' to carry out the action. Therefore, the coordination recognizes the importance of the Project, which is strengthened based on each element inserted in the development of its respective editions.
\end{abstract}

Keywords: Evaluation, Pedagogical Practice, Teaching-learning. 